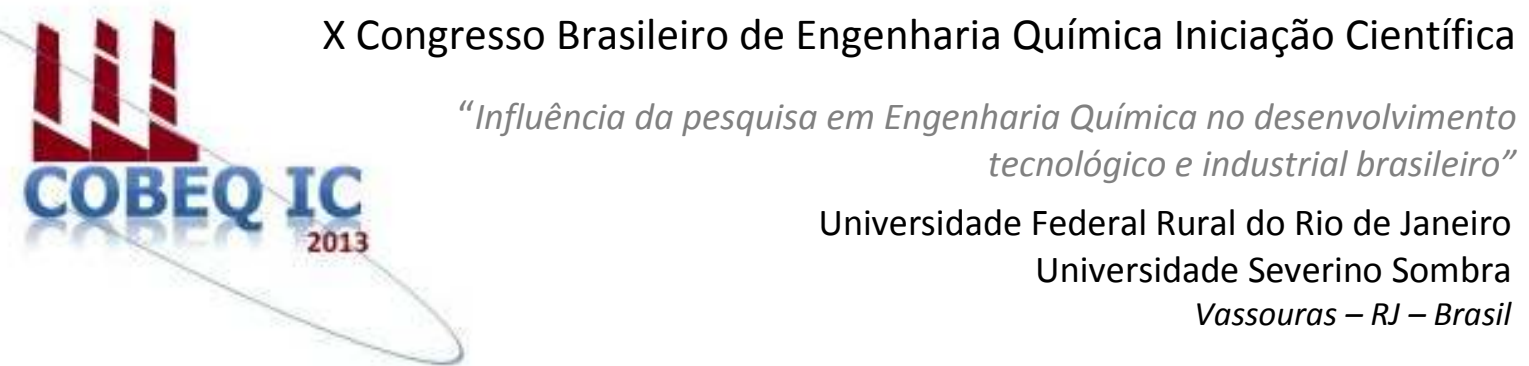

\title{
AVALIAÇÃO DO PODER GERMINATIVO E TEOR DE PROTEÍNA PARA SEMENTES DE CEVADA BRASILEIRA COM VISTAS AO PROCESSO DE MALTEAÇÃO
}

\author{
GOUVÊA ${ }^{1}$, L. F. C.; MAIA ${ }^{2}$, G. D. \\ ${ }^{1}$ Aluno do DQ/UNIFAL ${ }^{2}$ Professor do DEQ/UFSCar \\ Departamento de Engenharia Química - Universidade Federal de São Carlos \\ Endereço - UFSCar, Rodovia Washington Luís - SP-310, km 235, São Carlos, CEP. 13565-905, SP. \\ email: maia@ufscar.br
}

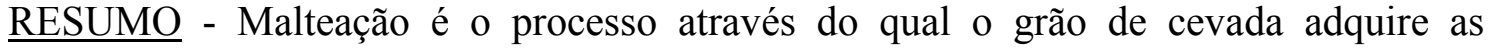
enzimas necessárias para a etapa de fermentação no processo de produção da cerveja. $\mathrm{O}$ processo de malteação consiste na germinação controlada dos grãos de cevada e posterior secagem, a fim de produzir as características desejadas do malte, em função da demanda do mestre cervejeiro. Portanto, o objetivo do presente trabalho foi determinar e avaliar o poder germinativo, teor de nitrogênio e proteína das sementes de cevadas brasileiras dos tipos Brau, Caue e Elis, tradicionalmente utilizadas para fins de malteação, além de avaliar quais tipos de cevada apresentam aspectos físiológicos compatíveis com o processo de malteação. Concluiu-se, com o presente estudo, que todas as variedades estudadas apresentaram poder germinativo e teor de proteína compatível com o esperado, para que a cevada seja destinada à malteação.
\end{abstract}

Palavras chave: qualidade, malte, cerveja.

\section{INTRODUÇÃO}

Conforme estabelecido pelo Duque da Baviera, na conhecida Lei de Pureza Alemã de 1516 - "The Reinheitsgebot", os elementos permitidos para a fabricação de cerveja são o malte de cevada, lúpulo e água (Palmer, 2006). Dessa forma, para a produção de cerveja tornase imperativo a produção de malte de cevada.

A Agência Nacional de Vigilância Sanitária (Anvisa) define malte como sendo o produto resultante da germinação e posterior dessecação do grão de cevada da espécie Hodeum sativum. Quando o produto derivar de outro cereal, deverá conter o nome de tal cereal após a designação "malte" (Brasil, 1978).

Sendo o malte o principal agente sacarificante na fabricação de cerveja, o processo de maltagem é realizado pela indústria cervejeira a fim de produzir enzimas (principalmente $\alpha, \beta$-amilase e maltase) no grão do cereal e causar mudanças químicas em seus constituintes para que este seja a fonte de açúcares fermentescíveis (Aquarone et al, 1983).

Para deter o processo de germinação utiliza-se da secagem, onde a sobrevivência das enzimas de interesse dependerá do tempo e da temperatura em que o grão é exposto (Aquarone et al, 1983). Entretanto, é o 
processo de secagem que define as características finais do malte, que servem de base para a receita estipulada pelo mestre cervejeiro.

Para o sucesso do processo de malteação, é fundamental que a cevada apresente características, em termos do poder germinativo e do teor de proteína, capazes de atender às exigências de qualidade desejáveis para a produção de malte de excelência.

As especificidades morfológicas da cevada brasileira, frente à europeia, a carência de informações sobre o processo de malteação para a cevada nacional e a necessidade de caracterização da matéria prima justificam o estudo dessas particularidades relativas à cevada nacional.

Dessa forma, o presente estudo teve como objetivo determinar o teor de nitrogênio e proteína, do poder germinativo e, em função dessas análises, avaliar quais espécies de cevadas seriam mais adequadas para $o$ processo de malteação

\section{Malteação}

A produção de malte é a primeira etapa para a produção de cerveja, visto que para produzir um hectolitro da bebida, são necessários aproximadamente dezessete quilos de malte de cevada.

Em cervejarias de larga produção, parte do malte de cevada é substituído por cereais não maltados, a fim de baratear o produto final. Isso não ocorre com cervejas do tipo super premium, sendo intituladas cervejas puro malte, justificando a importância do processo (Kunze, 2004).

A finalidade do processo de malteação é a produção de enzimas resultantes da germinação do grão de cevada, as quais terão fundamental importância na quebra do amido presente no endosperma do malte.

As etapas que constituem o processo de malteação englobam a maceração - ou umidificação - germinação e secagem.

A etapa de germinação é interrompida pelo processo de secagem, dando origem ao malte do grão correspondente e cujas propriedades são altamente dependentes das condições do grão em cada etapa do processo (Kunze, 2004).
$\mathrm{O}$ entendimento e o controle dessas variáveis no processo de malteação, juntamente com as análises preliminares da matéria-prima correspondente, são indispensáveis na produção de um produto final de qualidade.

Maceração: $O$ início da germinação da cevada ocorre somente a partir de um determinado teor de umidade.

A cevada armazenada possui um teor de umidade em torno de $12 \%$ (água de constituição), que deve ser mantido baixo, de modo a manter a taxa de respiração em níveis mínimos. Somente após a adição da água inicia-se o processo de germinação.

Germinação: A germinação é um processo fisiológico, em que os órgãos do embrião - radícula e acrospira - se desenvolvem, graças aos nutrientes armazenados no corpo farinhoso.

A germinação só ocorre sob determinadas condições: umidade suficiente, calor e oxigênio.

Para uma germinação homogênea, são necessários teores de umidade de $44-48 \%$ $(50 \%)$ e temperaturas entre 14 a 18 graus Celsius.

A energia necessária para a germinação é coberta pela respiração. Com isso o oxigênio atmosférico torna-se imprescindível para o crescimento (Aquarone et al, 1983).

Secagem: O malte verde, com seu elevado teor de umidade, é susceptível a rápida deterioração e, por isto, através do processo de secagem, pode ser adequadamente estocado.

Além disso, é necessário finalizar as transformações bioquímicas, a fim de fixar a composição do malte.

$\mathrm{O}$ odor e paladar cru do malte verde devem ser eliminados e substituídos pelo aroma e paladar característicos do malte pronto, assim como a cor.

A eliminação das radículas é necessária, pois elas transmitem um paladar amargo adstringente à cerveja e são higroscópicas (Priest et al, 2006).

Estes objetivos são alcançados através dos processos de pré-secagem e secagem final.

O processo de secagem final também é conhecido como kilning (Priest et al, 2006). 


\section{MATERIAIS E MÉTODOS}

\section{Poder Germinativo}

O teste de germinação tem por objetivo determinar o potencial máximo de germinação de um lote de sementes, o qual pode ser usado para comparar a qualidade de diferentes lotes e também estimar o valor para semeadura em campo.

A realização deste teste em condições de campo não é geralmente satisfatória, pois, dada a variação das condições ambientais, os resultados nem sempre podem ser fielmente reproduzidos (Brasil, 2009).

Nos testes de laboratório, a porcentagem de germinação de sementes corresponde à proporção do número de sementes que produziu plântulas classificadas como normais, em condições e períodos especificados.

O procedimento adotado foi o descrito pela RAS (Regra para Análise de Sementes). Para o caso da cevada do gênero Hordeum vulgare $\mathrm{o}$ período especificado para a germinação é de 7 (sete) dias com a primeira contagem das sementes germinadas realizada no terceiro dia após a encubação em germinadora sob condições de temperatura de $20{ }^{\circ} \mathrm{C}$ e umidade superior a $96 \%$.

O substrato utilizado foi papel toalha com a disposição de sementes entre camadas.

A Figura 1 ilustra a disposição das sementes para o teste de poder germinativo.

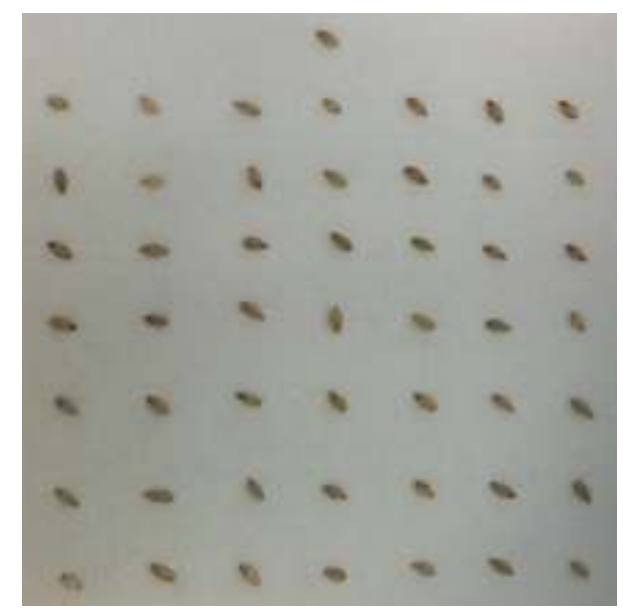

Figura 1. Disposição das sementes em substrato para a determinação do poder germinativo.
Não são especificadas condições de foto período, mas aconselha-se um mínimo de 8 horas de claridade para melhor desenvolvimento das plântulas. (Brasil, 2009).

\section{Teores de Nitrogênio e Proteína}

$\mathrm{O}$ teor de proteínas totais baseia-se na determinação de nitrogênio realizado através do método de Kjeldahl.

A proteína presente no grão de cevada é extremamente útil na regulagem da germinação em condições favoráveis e como substrato das leveduras no processo de fermentação (Kunze, 2004).

O método é composto por três etapas: digestão ácida, destilação e titulação. $\mathrm{Na}$ digestão com ácido sulfúrico concentrado, a matéria orgânica triturada em um moinho da marca Tekmar A-10 é decomposta e o nitrogênio presente se converte em sulfato de amônio (Zenebon et al, 2008).

Uma massa precisa da amostra triturada é, então, transferida para o frasco Kjeldahl a fim de se proceder com a digestão ácida.

A amostra recebe, então, sete mililitros de ácido sulfúrico concentrado da marca Sinth e uma ponta de espátula de catalisador. A digestão ácida tem início em um digestor da marca Büchi.

Inicialmente a temperatura é regulada na escala 4 do equipamento, correspondente à temperatura de digestão de $200^{\circ} \mathrm{C}$.

Após uma hora de digestão a escala é alterada para 6 até uma temperatura de digestão de $450{ }^{\circ} \mathrm{C}$. Considera-se que a digestão estará completa quando a solução se apresentar transparente e azulada.

Em seguida, é realizada a neutralização do sulfato de amônio formado na digestão com hidróxido de sódio $40 \% \mathrm{~m} / \mathrm{v}$ em excesso, tendo como produtos a amônia, sulfato de sódio e moléculas de água.

Logo após a neutralização, a destilação será responsável por evaporar o componente mais volátil, a amônia, que será resfriada no condensador e armazenada em um erlenmeyer contendo $20 \mathrm{ml}$ de ácido bórico da marca Chemis, em solução de $4 \% \mathrm{~m} / \mathrm{v}$, formando o borato de amônio segundo a reação química a seguir (Zenebon et al, 2008). 
O equipamento utilizado nessa etapa foi o destilador Büchi Destilation Unit B-323, como mostra a Figura 2.

Em seguida, realiza-se a titulação do borato de amônio com ácido clorídrico $0,05 \mathrm{M}$ até o ponto de viragem, anotando o volume gasto na neutralização do titulado. $\mathrm{O}$ indicador utilizado foi uma mistura de verde de bromocresol e vermelho de metila.

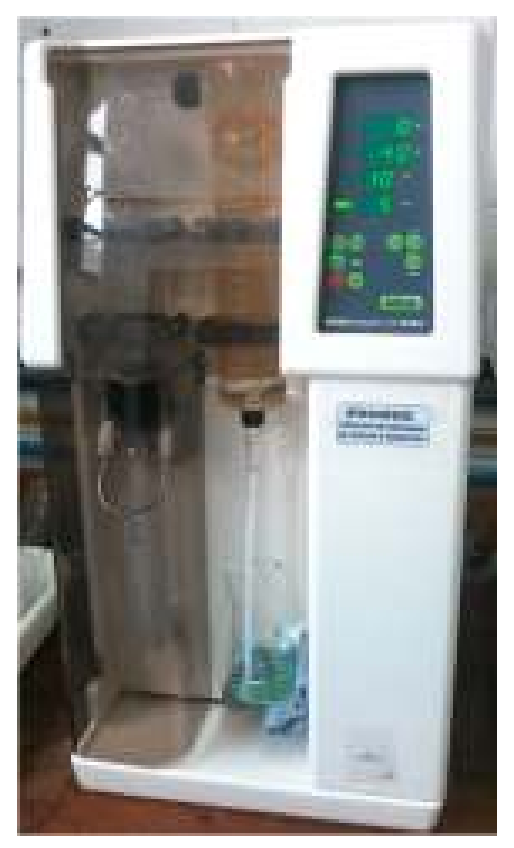

Figura 2: Destilador Büchi.

O cálculo final do teor de nitrogênio é realizado com a Equação 1.

$$
\% N=\frac{V \cdot C_{H C l} \cdot 0,014 \cdot 100}{M}
$$

A padronização foi realizada em triplicata, titulando cerca de 0,5 grama de bórax solubilizado em $50 \mathrm{~mL}$ de água o com ácido clorídrico presente em uma bureta de 50 $\mathrm{mL}$. Adiciona-se o indicador (fenolftaleína) aos erlenmeyers contendo o bórax solubilizado e inicia-se a titulação.

\section{RESULTADOS E DISCUSSÕES}

\section{Poder Germinativo}

Ao fim do processo para a determinação do poder germinativo das três variedades de cevada em questão - Elis, Brau e Caue realizados com uma amostra original e três réplicas, foram obtidos os resultados mostrados nas Tabelas 1,2 e 3 .

\section{Tabela 1. Poder Germinativo (PG) da cevada da espécie Elis.}

\begin{tabular}{cccc}
\hline Amostra & $\begin{array}{c}n^{\circ} \\
\text { sementes }\end{array}$ & $\begin{array}{c}n^{\circ} \\
\text { germinadas }\end{array}$ & $P G$ \\
\hline R0 & 100 & 99 & $99 \%$ \\
R1 & 100 & 100 & $100 \%$ \\
R2 & 100 & 99 & $99 \%$ \\
R3 & 100 & 100 & $100 \%$ \\
\hline Média & & & 99,5 \\
\hline
\end{tabular}

O desvio padrão populacional $(\sigma)$ para o PG da cevada tipo BRS Elis pode ser determinado através da Equação 2.

$$
\sigma=\sqrt{\sum_{i=1}^{n} \frac{\left(x_{i}-\mu\right)^{2}}{N}}
$$

Para o presente experimento o desvio padrão calculado foi de $\pm 0,25$ e uma variância $\sigma^{2}$ de 0,5 . Ambos os valores são aceitáveis tendo em vista o tamanho da amostra e sua reprodutibilidade em quadruplicata.

$\mathrm{O}$ coeficiente de variação $\mathrm{cv}$, que representa o desvio-padrão expresso como porcentagem da média, dado pela relação entre desvio padrão e o valor da média, alcança valores de $0,50 \%$, de forma que se pode afirmar que os desvios em relação à média são pouco significativos.

\section{Tabela 2. Poder Germinativo (PG) da cevada da espécie Brau.}

\begin{tabular}{cccc}
\hline Amostra & $\begin{array}{c}n^{\circ} \\
\text { sementes }\end{array}$ & $\begin{array}{c}n^{\circ} \\
\text { germinadas }\end{array}$ & $P G$ \\
\hline R0 & 100 & 93 & $93 \%$ \\
R1 & 100 & 100 & $100 \%$ \\
R2 & 100 & 97 & $97 \%$ \\
R3 & 100 & 93 & $93 \%$ \\
\hline Média & & & 95,75 \\
\hline
\end{tabular}

Para a cevada do tipo Brau o desvio padrão calculado foi da ordem de $\pm 2,95$, com uma variância $\sigma^{2}$ de 8,69 e um coeficiente de variação da ordem de 3,08\%. 
Tabela 3. Poder Germinativo (PG) da cevada BRS Caue.

\begin{tabular}{cccc}
\hline Amostra & $\begin{array}{c}n^{\circ} \\
\text { sementes }\end{array}$ & $\begin{array}{c}n^{\circ} \\
\text { germinadas }\end{array}$ & $P G$ \\
\hline R0 & 100 & 94 & $94 \%$ \\
R1 & 100 & 93 & $93 \%$ \\
R2 & 100 & 98 & $98 \%$ \\
R3 & 100 & 96 & $96 \%$ \\
\hline Média & & & 95,25 \\
\hline
\end{tabular}

Para os dados de PG obtidos para a variedade Caue, o desvio padrão calculado foi da ordem de $\pm 1,92$, sua variância $\sigma^{2}$ foi de 3,68 e seu coeficiente de variação atingiu valores de $2,02 \%$.

Assim como observado para a variedade Brau, as sementes da espécie Caue apresentavam características visuais satisfatórias, como a coloração amarelo-palha, boa rugosidade da casca e rigidez dentro do aceitável. (Santos et al, 2010)

\section{Teores de Nitrogênio e Proteína}

Efetuou-se o procedimento correspondente ao Método de Kjeldahl para uma série de amostras das três variedades de cevada em estudo.

Os valores calculados em 13 ensaios para as três espécies de cevada estudadas encontram-se sumarizados na Tabela 4.

A concentração de ácido clorídrico utilizada para todas as análises foi determinada por padronização como $0,051 \mathrm{M}$.

\section{Tabela 4. Teores de nitrogênio e proteína para as espécies de cevada.}

\begin{tabular}{ccccc}
\hline Espécie & $\% N$ & $\% P$ & $(\sigma)$ & $\left(\sigma^{2}\right)$ \\
\hline Caue & 2,04 & 11,76 & $\pm 0,10$ & 0,010 \\
Brau & 1,96 & 11,44 & $\pm 0,06$ & 0,004 \\
Elis & 1,74 & 10,16 & $\pm 0,07$ & 0,005 \\
\hline
\end{tabular}

Todas as variedades apresentaram um teor de proteínas condizentes com a literatura: entre 9,5\% a 11,5\% (Kunze, 2004).

Isso implica que os maltes formados a partir dessas cevadas têm condições de fornecer subprodutos proteicos suficientes na forma de nutrientes essenciais para as leveduras no processo de fermentação.

A variedade Elis mostrou a menor porcentagem de proteínas totais, $10,16 \%$, mas, ainda sim, dentro da média padrão.

Essa análise associada ao sucesso nos ensaios de poder germinativo pode sugerir que a conversão da proteína em subprodutos proteicos será efetiva.

A variedade Brau apresentou uma quantidade de proteínas um pouco maior que a variedade Elis, ainda assim dentro dos valores normais.

O baixo coeficiente de variação indica uma homogeneidade adequada quanto à composição proteica dos grãos no lote.

\section{CONCLUSÕES}

Todas as variedades de cevada testadas apresentam valores adequados de suas propriedades sendo todas viáveis para a malteação.

\section{NOMENCLATURA}

$\mathrm{C}_{\mathrm{HCl}}$ : concentração de $\mathrm{HCl}(\mathrm{M})$.

M: massa de cevada triturada (mg).

$N$ : número de elementos na população.

$\mathrm{V}$ : volume titulado $(\mathrm{mL})$.

$x_{i}$ : valor do iésimo elemento da população.

$\mu$ : média dos valores.

$\sigma:$ desvio padrão populacional.

$\sigma^{2}$ : variância.

\section{REFERÊNCIAS}

AQUARONE, E., LIMA, U. A., BORZANI, W. (1983), Alimentos e Bebidas Produzidos por Fermentação. Edgard Blücher. São Paulo, 227p.

BRASIL (1978), Agência Nacional de Vigilância Sanitária. Resolução - CNNPA $\mathrm{n}^{\circ} 12$, de 1978. Brasília, DF.

BRASIL (2009), Ministério da Agricultura. Regras Para Análises de Sementes. Brasília, DF.

KUNZE, W. (2004), Technology of Brewing and Malting. Terceira edição. Editora Westkreuz-Druckerei Ahrens KG. Berlin, 948 . 
PRIEST, F. G.; STEWART, G. G. (2006), Handbook of Brewing. Second Edition, Food Science and Technology, Ed. Taylor and Francis Group, LLC, USA,860p.

SANTOS, I. J.; SANTOS, Y. L.; da SILVA, P. H. A. Curvas de Dois Processos de Hidratação da Cevada. Revista Brasileira de Produtos Agroindustriais, Campina Grande, v.12, n.1, p.1-8, 2010.

ZENEBON, O.; PASCUET, N. S.; TIGLEA, P. (2008), Métodos Físico-Químicos para Análise de Alimentos. Quarta edição. São Paulo, 2008.

\section{AGRADECIMENTOS}

Os autores agradecem a Cooperativa Agrária Agroindustrial pela inestimável contribuição ao presente trabalho através do fornecimento dos lotes de cevada para as análises. 